\title{
Assessment of quality of life in women using Femelis Meno
}

\author{
Tomasz Paszkowski ${ }^{1}$, Violetta Skrzypulec-Plinta² \\ ${ }^{1} 3^{\text {rd }}$ Chair and Department of Gynecology, Medical University of Lublin, Lublin, Poland \\ ${ }^{2}$ Chair of Women's Health, Medical University of Silesia in Katowice, Katowice, Poland
}

\begin{abstract}
Over $30 \%$ of women suffering from menopausal symptoms use products of plant origin. This paper presents the results of a study devoted to evaluation of the efficacy of the Femelis Meno dietary supplement containing standardized flower pollen and pistil extracts (PI 82-GC FEM).
\end{abstract}

Key words: menopause, quality of life, phytotherapy.

\section{Introduction}

Publication of the Women's Health Initiative study (WHI) in 2002 and the results of the Million Women Study (MWS) published one year later raised a stormy discussion on the safety of hormonal menopausal therapy (HMT) that is still ongoing. A "side effect" of this debate, in particular of the one being conducted in nonmedical media, was a worldwide collapse of the HMT market [1]. Such a drastic fall in popularity of hormonal menopausal therapy is all the more surprising as many conclusions from the WHI and MWS studies are generally criticised by global experts in the field of menopause and were not confirmed in later clinical studies. Hormonal menopausal therapy still remains the most effective method of elimination/reduction of the symptoms of oestrogen deficit, in particular of the vasomotor ones [2]. However, the reduced interest in hormonal menopausal therapy cannot go unnoticed or be underestimated. Over $30 \%$ of women suffering from menopausal symptoms use products of plant origin. Good Clinical Practice requires the doctor counselling on menopausal medicine to be ready to use a wide portfolio of various products intended to improve the quality of life of patients with menopausal symptoms [3].

The spectrum of currently available products for elimination/reduction of vasomotor symptoms related to oestrogen deficit includes the following:

- systemic hormonal therapy based on administration of oestrogen or oestrogen with a progestogen,

- antidepressants [selective serotonin reuptake inhibitors (SSRI)] - e.g. paroxetine, fluoxetine,

- phytoestrogens,

- non-hormonal phytotherapies.

The oncological safety profile of phytoestrogens, in particular those of soya origin, has been a subject of much controversy [4-6]. Non-hormonal phytotherapy is a new therapeutic alternative for patients suffering from menopausal symptoms. In this product group Femelis Meno seems the most promising. It contains, as active substances, standardised flower pollen and pistil extracts (PI 82-GC FEM) in combination with vitamin $E$ as an antioxidant (one tablet of this product contains $5 \mathrm{mg}$ of vitamin $\mathrm{E}$, which corresponds to $42 \%$ of the recommended daily intake). In a technologically advanced patented process of PI 82-GC FEM extraction, allergens contained in flower pollen are removed. A unique technology used for this purpose makes it possible to obtain purified cytoplasm of flower pollen cells through removal of the allergen-containing envelope. The specific flower pollen cytoplasm obtained with this method contains active substances of very high bioavailability after oral administration. Owing to complete elimination of flower pollen allergens in this process, the product obtained in this way may also be used in women with allergies of different types. The main component of the active substance contained in Femelis Meno is extract PI 82 obtained from pollen of Secale cereale, Dactylis glomerata and Pinus sylvestris flowers. PI 82 also contains extracts from pollens and pistils of the Zea mays flower. The second active substance contained in Femelis Meno, called GC FEM, is the extract from Secale cereale, Zea mays and Pinus sylvestris pollen. Each tablet of Femelis Meno contains $160 \mathrm{mg}$ of the extracts, in the following proportion: $75 \% \mathrm{PI} 82$ and $25 \%$ GC FEM. Flower pollen and pistils are selected and collected in a standardised manner in Sweden, and both the culture of flower plant species and the process of active substance extraction occur under strict quality control. This product was launched in Sweden in 1995, and now it is available under different names in 15 countries. 
Table 1. Characteristics of the studied group $(n=50)$

\begin{tabular}{lcccc}
\hline Variable & Median & Minimum & Maximum & Range \\
\hline Age (years) & 54.0 & 46.0 & 65.0 & 19.0 \\
\hline Height $(\mathrm{cm})$ & 168.0 & 147.0 & 180.0 & 33.0 \\
\hline Weight $(\mathrm{kg})$ & 79.0 & 57.0 & 96.0 & 39.0 \\
\hline
\end{tabular}

The efficacy of this product in alleviation of vasomotor menopausal symptoms was discovered by chance during a clinical study assessing its effects in elderly women and men. During this study it was found that such vasomotor symptoms as hot flushes are significantly reduced in peri- and postmenopausal women using this product. Active substances contained in Femelis Meno do not show any hormonal mechanisms of action typical for oestrogens or phytoestrogens. PI 82-GC FEM extracts used in Femelis Meno are believed to have similar activity as the SSRIs, regulating serotonergic neuron functions in the brain that control thermoregulation, mood and sleep. Flower pollen/pistil extracts used in Femelis Meno were found to inhibit the uptake of labelled serotonin in cortical synaptosomes in rats.

Use of flower pollens for medical purposes dates back to ancient Egypt and China, where flower pollen was used to improve energy flow and to treat menstrual disorders as early as 200 B.C. Flower pollen contains microgametophytes of plants producing male germ cells. The cytoplasm of a particle of flower pollen, containing the genetic material, is protected by an envelope resembling a shell, whose dissolution (e.g. by gastric acid) is a prerequisite for bioavailability of the active pollen components. Flower pollen is composed of about $25 \%$ proteins and contains more than 130 active ingredients, i.e. amino acids (including tryptophan), vitamins, microand macroelements, fatty acids and antioxidants (e.g. superoxide dismutase) [8-11].

The objective of this study was to assess the impact of Femelis Meno use on the quality of life of women suffering from menopausal symptoms. The patients' satisfaction with the therapy was also assessed.

\section{Material and methods}

This observational study included women with menopausal symptoms significantly worsening their quality of life. A study questionnaire was used that consisted of 3 parts: a sociometric interview, an obstetrical and gynaecological interview and a part assessing various quality of life aspects with two standardised questionnaires:
- Menopause Rating Scale (MRS),

- Female Sexual Functioning Inventory (FSFI). The study included 3 visits:

- visit 1 - qualification visit: medical history and physical examination, study course description, questionnaires, dispensing the dietary supplement along with the instructions how to use it,

- visit 2 - one month from the commencement of the use of Femelis Meno: questionnaires, physical examination,

- visit 3 -after 3 months of the use of Femelis Meno: questionnaires, physical examination; assessment of patient's satisfaction with the therapy.

The study was conducted at two research sites: in Katowice and in Lublin. In both sites 50 women were recruited in total, based on the following inclusion/exclusion criteria:

$$
\text { Inclusion criteria: }
$$

- women with menopausal symptoms - at least 35 episodes of moderate or severe hot flushes within the last 7 weeks,

- consent to take part in the study,

- regular intake of Femelis Meno (1 tablet BID), in accordance with the instructions,

- participation in all study visits (I, II, III),

- correct completion of the survey questionnaires. Exclusion criteria:

- withdrawal of the consent for participation in the study at any stage of the study,

- use of any menopausal therapy (hormonal or phytotherapy) within the last 3 months,

- failure to complete all 3 scheduled visits,

- incorrect completion of any of the study questionnaires,

- somatic diseases/mental disorders that might affect the studied aspects of the quality of life.

Table 1 presents the characteristics of the studied women.

Sixty-eight percent of the studied women were postmenopausal whereas $32 \%$ still had irregular menstrual bleeding. In the studied population, median age at menarche was 13 years (10-14 years) and median age at menopause was 53 years (46-55 years). Nulliparous women represented $8 \%$ of the studied population. Median parity in the studied group of women was 2 [1-4].

\section{Results}

Tables 2-4 and Figure 1 show the comparisons of the number of hot flushes before and during therapy.

Table 2. Numbers of hot flushes in the studied women before the start and after one month of the use of Femelis Meno $(n=50)$

\begin{tabular}{lccccc}
\hline Hot flushes & & Median & Minimum & Maximum & Wilcoxon test \\
\hline $\begin{array}{l}\text { Number of episodes of hot flushes } \\
\text { (moderate/severe) per week }\end{array}$ & Visit 1 & 15.0 & 35.0 & 60.0 & -3.164 \\
\cline { 2 - 6 } & Visit 2 & 5.5 & 0.0 & 34.0 & $p=0.002$ \\
\hline
\end{tabular}


Table 3. Numbers of hot flushes in the studied women after one month and after three months of the use of Femelis Meno $(n=50)$

\begin{tabular}{lccccc}
\hline Hot flushes & & Median & Minimum & Maximum & Wilcoxon test \\
\hline $\begin{array}{l}\text { Number of episodes of hot } \\
\text { flushes (moderate/severe) }\end{array}$ & Visit 2 & 5.5 & 0.0 & 34.0 & -3.008 \\
\cline { 2 - 5 } & Visit 3 & 2.0 & 0.0 & 22.5 & $p=0.003$ \\
\hline
\end{tabular}

Table 4. Numbers of hot flushes in the studied women before the start and after three months of the use of Femelis Meno $(n=50)$

\begin{tabular}{lccccc}
\hline Hot flushes & & Median & Minimum & Maximum & Wilcoxon test \\
\hline $\begin{array}{l}\text { Number of episodes of hot } \\
\text { flushes (moderate/severe) }\end{array}$ & Visit 1 & 15.0 & 35.0 & 60.0 & -3.441 \\
\cline { 2 - 6 } & Visit 3 & 2.0 & 0.0 & 22.5 & $p=0.001$ \\
\hline
\end{tabular}

Significant improvement was observed as early as after one month and this improvement was more pronounced after the subsequent two months of the treatment with Femelis Meno.

Table 5 presents the results of treatment with respect to 11 parameters assessed with the MRS scale. Tables 6-8 present the significance of the differences between the parameters assessed using the MRS scale before and during the therapy. After one month of treatment significant improvement was noted with respect to such parameters as hot flushes/sweating, irritability, sexual problems and bladder problems. When comparing the symptomatic status between visits 1 and 3 (Table 8), a significant improvement was observed for almost all parameters analysed with the MRS scale, except for joint and muscle discomfort.

Tables 9-11 illustrate the differences in six domains analysed with the FSFI questionnaire, reflecting the sexual life quality before and during the therapy. After one month of treatment, significant improvement was observed only with respect to sexual satisfaction (Table 9) and there was no statistically significant change in the total FSFI score. After the subsequent 2 months of the therapy, there was a statistically significant improvement with respect to 2 domains (arousal and lubrication) and of the FSFI total score, as compared to the pre-treatment status.

Tables 12-14 compare the proportion of patients with clinically significant disorders (FSFI total $\leq 26.55)$ before and during the therapy. This percentage decreased from $68 \%$ before the treatment to $44 \%$ after 3 months of treatment (Table 13), but this change did not reach statistical significance.

As shown in Table 15, after 3 months of treatment with Femelis Meno $80 \%$ of the studied patients gave positive responses to the question about their satisfaction with the results of the treatment $(56.0 \%$ were very satisfied, and $24 \%$ were rather satisfied).

The question Would you recommend Femelis Meno to other women suffering from menopausal symptoms? was answered "certainly yes" by $64 \%$ of the respondents, and "probably yes" by another $16 \%$ of them. Only $4 \%$ of the studied women answered this question with "certainly not" (Table 16).

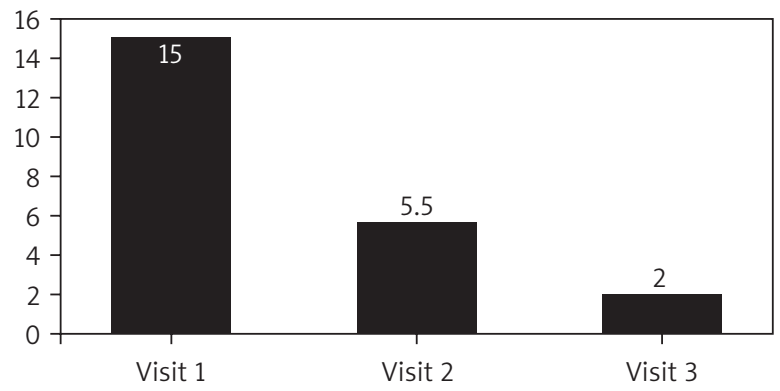

Fig. 1. Average (median) numbers of hot flushes in the studied women

\section{Discussion}

Vasomotor symptoms are the most common and one of the most burdensome menopausal symptoms, and among them hot flushes are the most commonly reported by the patients [2]. To a various extent, this symptom worsens the quality of life in approximately $50 \%$ of peri- and postmenopausal women. Over $25 \%$ of women have severe or moderate hot flushes. Such women were included in the efficacy study of Femelis Meno. The study has shown very good efficacy of the product with respect to elimination of vasomotor symptoms as early as after 4 weeks of the treatment, and this effect increased during the subsequent months of the treatment.

This study demonstrated that the benefits from the use of Femelis Meno in perimenopausal women are multidirectional in nature and pertain to many both somatic and non-somatic elements responsible for the quality of life. The results of our study confirm the results obtained by other researchers. Elia and Mares [12] studied 417 menopausal women suffering from menopausal symptoms, in particular from vasomotor ones. For 84 days, these patients received a product of the same composition as Femelis Meno (GC FEM $40 \mathrm{mg}, \mathrm{Pl} 120 \mathrm{mg}$, Vitamin E $82.5 \mathrm{mg}$ ), 1 tablet twice daily. The efficacy and tolerance profile of this therapy were assessed. Mean age of the patients was 54.4 years. Based on the visual analogue scale (VAS), significant improvement of sleep quality and general quality of life was found. Improvement of hot flushes and excessive 
Table 5. Response of the studied women to treatment with respect to the severity of menopausal symptoms by visit $(n=50)$ - results of examination with the Menopause Rating Scale (MRS)

\begin{tabular}{|c|c|c|c|c|c|c|c|c|c|c|c|c|c|}
\hline \multirow{2}{*}{$\begin{array}{l}\text { Menopausal } \\
\text { symptoms }\end{array}$} & & \multicolumn{2}{|c|}{ None } & \multicolumn{2}{|c|}{ Mild } & \multicolumn{2}{|c|}{ Moderate } & \multicolumn{2}{|c|}{ Severe } & \multicolumn{2}{|c|}{ Very severe } & \multicolumn{2}{|c|}{ No data } \\
\hline & & $n$ & $\%$ & $n$ & $\%$ & $n$ & $\%$ & $n$ & $\%$ & $n$ & $\%$ & $n$ & $\%$ \\
\hline \multirow{3}{*}{$\begin{array}{l}\text { Hot flushes, } \\
\text { sweating }\end{array}$} & Visit 1 & 0 & - & 0 & - & 14 & 28.0 & 18 & 36.0 & 18 & 36.0 & - & - \\
\hline & Visit 2 & 6 & 12.0 & 16 & 32.0 & 14 & 28.0 & 10 & 20.0 & 4 & 8.0 & - & - \\
\hline & Visit 3 & 18 & 36.0 & 24 & 48.0 & 2 & 4.0 & 2 & 4.0 & 4 & 8.0 & - & - \\
\hline \multirow{3}{*}{$\begin{array}{l}\text { Heart } \\
\text { problems }\end{array}$} & Visit 1 & 8 & 16.0 & 14 & 28.0 & 16 & 32.0 & 12 & 24.0 & - & - & - & - \\
\hline & Visit 2 & 8 & 16.0 & 18 & 36.0 & 12 & 24.0 & 12 & 24.0 & - & - & - & - \\
\hline & Visit 3 & 20 & 40.0 & 12 & 44.0 & 6 & 12.0 & 2 & 4.0 & - & - & - & - \\
\hline \multirow{3}{*}{$\begin{array}{l}\text { Sleeping } \\
\text { disorders }\end{array}$} & Visit 1 & 10 & 20.0 & 18 & 36.0 & 14 & 28.0 & 8 & 16.0 & - & - & - & - \\
\hline & Visit 2 & 12 & 24.0 & 16 & 32.0 & 16 & 32.0 & 6 & 12.0 & - & - & - & - \\
\hline & Visit 3 & 22 & 44.0 & 18 & 36.0 & 6 & 12.0 & - & - & 2 & 4.0 & 2 & 4.0 \\
\hline \multirow{3}{*}{$\begin{array}{l}\text { Depressive } \\
\text { mood }\end{array}$} & Visit 1 & 8 & 16.0 & 12 & 24.0 & 22 & 44.0 & 8 & 16.0 & - & - & - & - \\
\hline & Visit 2 & 12 & 24.0 & 20 & 40.0 & 10 & 20.0 & 8 & 16.0 & - & - & - & - \\
\hline & Visit 3 & 28 & 56.0 & 14 & 28.0 & 4 & 8.0 & 2 & 4.0 & - & - & 2 & 4.0 \\
\hline \multirow[t]{3}{*}{ Irritability } & Visit 1 & 6 & 12.0 & 10 & 20.0 & 18 & 36.0 & 14 & 28.0 & - & - & 2 & 4.0 \\
\hline & Visit 2 & 10 & 20.0 & 18 & 36.0 & 16 & 32.0 & 4 & 8.0 & 2 & 4.0 & - & - \\
\hline & Visit 3 & 14 & 28.0 & 28 & 56.0 & 6 & 12.0 & 2 & 4.0 & - & - & - & - \\
\hline \multirow[t]{3}{*}{ Anxiety } & Visit 1 & 14 & 28.0 & 12 & 24.0 & 16 & 32.0 & 8 & 16.0 & - & - & - & - \\
\hline & Visit 2 & 16 & 32.0 & 18 & 36.0 & 6 & 12.0 & 8 & 16.0 & - & - & 2 & 4.0 \\
\hline & Visit 3 & 38 & 76.0 & 10 & 20.0 & 2 & 4.0 & - & - & - & - & - & - \\
\hline \multirow{3}{*}{$\begin{array}{l}\text { Physical } \\
\text { and mental } \\
\text { exhaustion }\end{array}$} & Visit 1 & 6 & 12.0 & 18 & 36.0 & 14 & 28.0 & 10 & 20.0 & - & - & 2 & 4.0 \\
\hline & Visit 2 & 6 & 12.0 & 26 & 52.0 & 12 & 24.0 & 4 & 8.0 & - & - & 2 & 4.0 \\
\hline & Visit 3 & 16 & 32.0 & 28 & 56.0 & 4 & 8.0 & 2 & 4.0 & - & - & - & - \\
\hline \multirow{3}{*}{$\begin{array}{l}\text { Sexual } \\
\text { problems }\end{array}$} & Visit 1 & 6 & 12.0 & 10 & 20.0 & 22 & 44.0 & 10 & 20.0 & 2 & 4.0 & - & - \\
\hline & Visit 2 & 8 & 16.0 & 30 & 60.0 & 6 & 12.0 & 4 & 8.0 & 2 & 4.0 & - & - \\
\hline & Visit 3 & 14 & 28.0 & 26 & 52.0 & 8 & 16.0 & 2 & 4.0 & - & - & - & - \\
\hline \multirow{3}{*}{$\begin{array}{l}\text { Bladder } \\
\text { problems }\end{array}$} & Visit 1 & 10 & 20.0 & 16 & 32.0 & 12 & 24.0 & 10 & 20.0 & 2 & 4.0 & - & - \\
\hline & Visit 2 & 16 & 32.0 & 16 & 32.0 & 10 & 20.0 & 6 & 12.0 & 2 & 4.0 & - & - \\
\hline & Visit 3 & 24 & 48.0 & 22 & 44.0 & 2 & 4.0 & 2 & 4.0 & - & - & - & - \\
\hline \multirow{3}{*}{$\begin{array}{l}\text { Vaginal } \\
\text { dryness }\end{array}$} & Visit 1 & 4 & 8.0 & 10 & 20.0 & 24 & 48.0 & 8 & 16.0 & 2 & 4.0 & 2 & 4.0 \\
\hline & Visit 2 & 6 & 12.0 & 16 & 32.0 & 24 & 48.0 & 2 & 4.0 & 2 & 4.0 & - & - \\
\hline & Visit 3 & 22 & 44.0 & 16 & 32.0 & 8 & 16.0 & 2 & 4.0 & - & - & 2 & 4.0 \\
\hline \multirow{3}{*}{$\begin{array}{l}\text { Joint and } \\
\text { muscle } \\
\text { discomfort }\end{array}$} & Visit 1 & 14 & 28.0 & 12 & 24.0 & 20 & 40.0 & 2 & 4.0 & 2 & 4.0 & - & - \\
\hline & Visit 2 & 14 & 28.0 & 18 & 36.0 & 16 & 32.0 & 2 & 4.0 & - & - & - & - \\
\hline & Visit 3 & 16 & 32.0 & 26 & 52.0 & 8 & 16.0 & - & - & - & - & - & - \\
\hline
\end{tabular}

sweating was highly statistically significant. Improvement of hot flushes (by more than $60 \%$, on average) was reported by $65 \%$ of the subjects. As many as $93 \%$ of the treated women were satisfied or very satisfied with their therapy, and $97.5 \%$ of the patients declared their willingness to continue the therapy after completion of the follow-up period. More than $98 \%$ of the subjects declared very good tolerance of this therapy.

Winther et al. [13] conducted a randomised placebo-controlled study to assess the efficacy of Femelis Meno in relieving menopausal symptoms, in particular of hot flushes. The studied population included 54 women, who were randomised to the therapy (2 tablets of Femelis Meno daily) or placebo for 3 months. The occurrence and severity of menopausal symptoms were measured with the Menopause Rating Scale (MRS). $65 \%$ of women in the group receiving Femelis Meno experienced alleviation of the hot flushes, whereas only $38 \%$ of patients from the control group receiving placebo reported improvement in this respect $(p<0.006)$ The number of hot flushes decreased by $27 \%$ in the Femelis Meno group, as compared to the control group $(p<0.026)$. Analysis of changes of 15 quality of life parameters showed a significantly better result in the 
Table 6. Severity of menopausal symptoms before the start and after one month of use of Femelis Meno $(n=50)-$ results of examination with the Menopause Rating Scale (MRS)

\begin{tabular}{|c|c|c|c|c|c|}
\hline Menopausal symptoms & & Median & Minimum & Maximum & Wilcoxon test \\
\hline \multirow[t]{2}{*}{ Hot flushes, sweating } & Visit 1 & 3.0 & 0.0 & 4.0 & -3.578 \\
\hline & Visit 2 & 2.0 & 0.0 & 4.0 & $p=0.000$ \\
\hline \multirow[t]{2}{*}{ Heart problems } & Visit 1 & 2.0 & 0.0 & 3.0 & -0.486 \\
\hline & Visit 2 & 1.0 & 0.0 & 3.0 & $p=0.627$ \\
\hline \multirow[t]{2}{*}{ Sleeping disorders } & Visit 1 & 1.0 & 0.0 & 3.0 & -0.486 \\
\hline & Visit 2 & 1.0 & 0.0 & 3.0 & $p=0.627$ \\
\hline \multirow[t]{2}{*}{ Depressive mood } & Visit 1 & 2.0 & 0.0 & 3.0 & -1.814 \\
\hline & Visit 2 & 1.0 & 0.0 & 3.0 & $p=0.070$ \\
\hline \multirow[t]{2}{*}{ Irritability } & Visit 1 & 2.0 & 0.0 & 3.0 & -2.179 \\
\hline & Visit 2 & 1.0 & 0.0 & 4.0 & $p=0.029$ \\
\hline \multirow[t]{2}{*}{ Anxiety } & Visit 1 & 1.0 & 0.0 & 3.0 & -1.222 \\
\hline & Visit 2 & 1.0 & 0.0 & 3.0 & $p=0.222$ \\
\hline \multirow[t]{2}{*}{ Physical and mental exhaustion } & Visit 1 & 1.5 & 0.0 & 3.0 & -1.615 \\
\hline & Visit 2 & 1.0 & 0.0 & 3.0 & $p=0.106$ \\
\hline \multirow[t]{2}{*}{ Sexual problems } & Visit 1 & 2.0 & 0.0 & 4.0 & -2.737 \\
\hline & Visit 2 & 1.0 & 0.0 & 4.0 & $p=0.006$ \\
\hline \multirow[t]{2}{*}{ Bladder problems } & Visit 1 & 1.0 & 0.0 & 4.0 & -2.309 \\
\hline & Visit 2 & 1.0 & 0.0 & 4.0 & $p=0.021$ \\
\hline \multirow[t]{2}{*}{ Vaginal dryness } & Visit 1 & 2.0 & 0.0 & 4.0 & -1.848 \\
\hline & Visit 2 & 2.0 & 0.0 & 4.0 & $p=0.065$ \\
\hline \multirow[t]{2}{*}{ Joint and muscle discomfort } & Visit 1 & 1.0 & 0.0 & 4.0 & -1.095 \\
\hline & Visit 2 & 1.0 & 0.0 & 3.0 & $p=0.273$ \\
\hline
\end{tabular}

Response rating: 0 - absent, 1 - mild, 2 - moderate, 3 - severe, 4 - very severe

Table 7. Severity of menopausal symptoms after one month and after three months of use of Femelis Meno $(n=50)-$ results of examination with the Menopause Rating Scale (MRS)

\begin{tabular}{|c|c|c|c|c|c|}
\hline Menopausal symptoms & & Median & Minimum & Maximum & Wilcoxon test \\
\hline \multirow[t]{2}{*}{ Hot flushes, sweating } & Visit 2 & 2.0 & 0.0 & 4.0 & -3.497 \\
\hline & Visit 3 & 1.0 & 0.0 & 4.0 & $p=0.000$ \\
\hline \multirow[t]{2}{*}{ Heart problems } & Visit 2 & 1.0 & 0.0 & 3.0 & -3.578 \\
\hline & Visit 3 & 1.0 & 0.0 & 3.0 & $p=0.000$ \\
\hline \multirow[t]{2}{*}{ Sleeping disorders } & Visit 2 & 1.0 & 0.0 & 3.0 & -0.486 \\
\hline & Visit 3 & 1.0 & 0.0 & 4.0 & $p=0.627$ \\
\hline \multirow[t]{2}{*}{ Depressive mood } & Visit 2 & 1.0 & 0.0 & 3.0 & -2.749 \\
\hline & Visit 3 & 0.0 & 0.0 & 3.0 & $p=0.006$ \\
\hline \multirow[t]{2}{*}{ Irritability } & Visit 2 & 1.0 & 0.0 & 4.0 & -2.012 \\
\hline & Visit 3 & 1.0 & 0.0 & 3.0 & $p=0.044$ \\
\hline \multirow[t]{2}{*}{ Anxiety } & Visit 2 & 1.0 & 0.0 & 3.0 & -3.573 \\
\hline & Visit 3 & 0.0 & 0.0 & 2.0 & $p=0.000$ \\
\hline \multirow[t]{2}{*}{ Physical and mental exhaustion } & Visit 2 & 1.0 & 0.0 & 3.0 & -2.653 \\
\hline & Visit 3 & 1.0 & 0.0 & 3.0 & $p=0.008$ \\
\hline \multirow[t]{2}{*}{ Sexual problems } & Visit 2 & 1.0 & 0.0 & 4.0 & -1.941 \\
\hline & Visit 3 & 1.0 & 0.0 & 3.0 & $p=0.052$ \\
\hline \multirow[t]{2}{*}{ Bladder problems } & Visit 2 & 1.0 & 0.0 & 4.0 & -3.218 \\
\hline & Visit 3 & 1.0 & 0.0 & 3.0 & $p=0.001$ \\
\hline \multirow[t]{2}{*}{ Vaginal dryness } & Visit 2 & 2.0 & 0.0 & 4.0 & -2.333 \\
\hline & Visit 3 & 1.0 & 0.0 & 3.0 & $p=0.020$ \\
\hline \multirow[t]{2}{*}{ Joint and muscle discomfort } & Visit 2 & 1.0 & 0.0 & 3.0 & -3.217 \\
\hline & Visit 3 & 1.0 & 0.0 & 2.0 & $p=0.001$ \\
\hline
\end{tabular}

Response rating: 0 - absent, 1 - mild, 2 - moderate, 3 - severe, 4 - very severe 
Table 8. Severity of menopausal symptoms before the start and after three months of use of Femelis Meno $(n=50)-$ results of examination with the Menopause Rating Scale (MRS)

\begin{tabular}{|c|c|c|c|c|c|}
\hline Menopausal symptoms & & Median & Minimum & Maximum & Wilcoxon test \\
\hline \multirow[t]{2}{*}{ Hot flushes, sweating } & Visit 1 & 3.0 & 0.0 & 4.0 & -4.061 \\
\hline & Visit 3 & 1.0 & 0.0 & 4.0 & $p=0.000$ \\
\hline \multirow[t]{2}{*}{ Heart problems } & Visit 1 & 2.0 & 0.0 & 3.0 & -3.311 \\
\hline & Visit 3 & 1.0 & 0.0 & 3.0 & $p=0.001$ \\
\hline \multirow[t]{2}{*}{ Sleeping disorders } & Visit 1 & 1.0 & 0.0 & 3.0 & -2.287 \\
\hline & Visit 3 & 1.0 & 0.0 & 4.0 & $p=0.022$ \\
\hline \multirow[t]{2}{*}{ Depressive mood) } & Visit 1 & 2.0 & 0.0 & 3.0 & -3.482 \\
\hline & Visit 3 & 0.0 & 0.0 & 3.0 & $p=0.000$ \\
\hline \multirow[t]{2}{*}{ Irritability } & Visit 1 & 2.0 & 0.0 & 3.0 & -3.508 \\
\hline & Visit 3 & 1.0 & 0.0 & 3.0 & $p=0.000$ \\
\hline \multirow[t]{2}{*}{ Anxiety } & Visit 1 & 1.0 & 0.0 & 3.0 & -3.616 \\
\hline & Visit 3 & 0.0 & 0.0 & 2.0 & $p=0.000$ \\
\hline \multirow[t]{2}{*}{ Physical and mental exhaustion } & Visit 1 & 1.5 & 0.0 & 3.0 & -2.982 \\
\hline & Visit 3 & 1.0 & 0.0 & 3.0 & $p=0.003$ \\
\hline \multirow[t]{2}{*}{ Sexual problems } & Visit 1 & 2.0 & 0.0 & 4.0 & -3.065 \\
\hline & Visit 3 & 1.0 & 0.0 & 3.0 & $p=0.002$ \\
\hline \multirow[t]{2}{*}{ Bladder problems } & Visit 1 & 1.0 & 0.0 & 4.0 & -3.630 \\
\hline & Visit 3 & 1.0 & 0.0 & 3.0 & $p=0.000$ \\
\hline \multirow[t]{2}{*}{ Vaginal dryness } & Visit 1 & 2.0 & 0.0 & 4.0 & -3.938 \\
\hline & Visit 3 & 1.0 & 0.0 & 3.0 & $p=0.000$ \\
\hline \multirow[t]{2}{*}{ Joint and muscle discomfort } & Visit 1 & 1.0 & 0.0 & 4.0 & -2.080 \\
\hline & Visit 3 & 1.0 & 0.0 & 2.0 & $p=0.38$ \\
\hline
\end{tabular}

Response rating: 0 - absent, 1 - mild, 2 - moderate, 3 - severe, 4 - very severe

Table 9. Differences between sexual life quality parameters in the studied women before the start and after one month of use of Femelis Meno $(n=50)$ - results of examination with the Female Sexual Functioning Inventory (FSFI)

\begin{tabular}{lccccc}
\hline Parameters of sexual life quality & & Median & Minimum & Maximum & Wilcoxon test \\
\hline \multirow{2}{*}{ Desire } & Visit 1 & 3.6 & 1.2 & 6.0 & 0.934 \\
\cline { 2 - 6 } & Visit 2 & 3.6 & 1.2 & 6.0 & $p=0.351$ \\
\hline \multirow{2}{*}{ Arousal } & Visit 1 & 3.6 & 0.9 & 6.0 & -0.205 \\
\cline { 2 - 5 } & Visit 2 & 3.9 & 0.0 & 5.4 & $p=0.838$ \\
\hline Lubrication & Visit 1 & 3.6 & 0.0 & 6.0 & 0.202 \\
\cline { 2 - 5 } & Visit 2 & 3.9 & 0.0 & 5.7 & $p=0.840$ \\
\hline Orgasm & Visit 1 & 3.6 & 1.6 & 6.0 & 0.901 \\
\cline { 2 - 5 } & Visit 2 & 4.0 & 0.0 & 5.6 & $p=0.367$ \\
\hline Sexual satisfaction & Visit 1 & 3.8 & 2.0 & 6.0 & 2.327 \\
\cline { 2 - 5 } & Visit 2 & 4.0 & 1.6 & 6.0 & -1.170 \\
\hline Pain & Visit 1 & 4.0 & 1.6 & 6.0 & $p=0.242$ \\
\cline { 2 - 5 } & Visit 2 & 3.6 & 0.0 & 6.0 & 0.465 \\
\hline Total & Visit 1 & 22.1 & 7.3 & 32.0 & $p=0.642$ \\
\cline { 2 - 5 } & Visit 2 & 23.2 & 3.7 & 32.8 & \\
\hline
\end{tabular}

group receiving Femelis Meno, as compared to the patients receiving placebo $(p<0.031)$. Only a few, clinically insignificant, adverse effects were noted in this study, and the tolerance profile of this product was highly rated by the patients.
In their congress report, Kimura and Gruber [14] confirmed the efficacy of a product with the same composition as Femelis Meno with respect to reduction of such menopausal symptoms as hot flushes (by 57.3\%), night sweats (by 62.6\%) and sleep disorders (by 54.7\%). No 
Table 10. Differences between sexual life quality parameters in the studied women after one and three months of use of Femelis Meno $(n=50)$ - results of examination with the Female Sexual Functioning Inventory (FSFI)

\begin{tabular}{|c|c|c|c|c|c|}
\hline Parameters of sexual life quality & & Median & Minimum & Maximum & Wilcoxon test \\
\hline \multirow[t]{2}{*}{ Desire } & Visit 2 & 3.6 & 1.2 & 6.0 & 1.407 \\
\hline & Visit 3 & 4.2 & 1.2 & 6.0 & $p=0.160$ \\
\hline \multirow[t]{2}{*}{ Arousal } & Visit 2 & 3.9 & 0.0 & 5.4 & 3.021 \\
\hline & Visit 3 & 4.8 & 1.5 & 6.0 & $p=0.003$ \\
\hline \multirow[t]{2}{*}{ Lubrication } & Visit 2 & 3.9 & 0.0 & 5.7 & 1.890 \\
\hline & Visit 3 & 4.8 & 0.0 & 6.0 & $p=0.059$ \\
\hline \multirow[t]{2}{*}{ Orgasm } & Visit 2 & 4.0 & 0.0 & 5.6 & 1.995 \\
\hline & Visit 3 & 4.4 & 0.0 & 6.0 & $p=0.046$ \\
\hline \multirow[t]{2}{*}{ Sexual satisfaction } & Visit 2 & 4.0 & 1.6 & 6.0 & 1.356 \\
\hline & Visit 3 & 4.8 & 0.8 & 6.0 & $p=0.175$ \\
\hline \multirow[t]{2}{*}{ Pain } & Visit 2 & 3.6 & 0.0 & 6.0 & 1.874 \\
\hline & Visit 3 & 4.8 & 0.0 & 6.0 & $p=0.061$ \\
\hline \multirow[t]{2}{*}{ Total } & Visit 2 & 23.2 & 3.7 & 32.8 & 1.917 \\
\hline & Visit 3 & 26.8 & 3.5 & 35.6 & $p=0.055$ \\
\hline
\end{tabular}

Table 11. Differences between sexual life quality parameters in the studied women before the start and after three months of use of Femelis Meno $(n=50)$ - results of examination with the Female Sexual Functioning Inventory (FSFI)

\begin{tabular}{|c|c|c|c|c|c|}
\hline Parameters of sexual life quality & & Median & Minimum & Maximum & Wilcoxon test \\
\hline \multirow[t]{2}{*}{ Desire } & Visit 1 & 3.6 & 1.2 & 6.0 & 1.913 \\
\hline & Visit 3 & 4.2 & 1.2 & 6.0 & $p=0.056$ \\
\hline \multirow[t]{2}{*}{ Arousal } & Visit 1 & 3.6 & 0.9 & 6.0 & 2.233 \\
\hline & Visit 3 & 4.8 & 1.5 & 6.0 & $p=0.026$ \\
\hline \multirow[t]{2}{*}{ Lubrication } & Visit 1 & 3.6 & 0.0 & 6.0 & 2.255 \\
\hline & Visit 2 & 4.8 & 0.0 & 6.0 & $p=0.024$ \\
\hline \multirow[t]{2}{*}{ Orgasm } & Visit 1 & 3.6 & 1.6 & 6.0 & 1.720 \\
\hline & Visit 3 & 4.4 & 0.0 & 6.0 & $p=0.085$ \\
\hline \multirow[t]{2}{*}{ Sexual satisfaction } & Visit 1 & 3.8 & 2.0 & 6.0 & 1.734 \\
\hline & Visit 2 & 4.8 & 0.8 & 6.0 & $p=0.083$ \\
\hline \multirow[t]{2}{*}{ Pain } & Visit 1 & 4.0 & 1.6 & 6.0 & 0.610 \\
\hline & Visit 3 & 4.8 & 0.0 & 6.0 & $p=0.542$ \\
\hline \multirow[t]{2}{*}{ Total } & Visit 1 & 22.1 & 7.3 & 36.0 & 2.133 \\
\hline & Visit 3 & 26.8 & 3.5 & 35.6 & $p=0.033$ \\
\hline
\end{tabular}

Table 12. Numbers of women with clinically significant sexual disorders before the start and after one month of use of Femelis Meno - results of examination with the Female Sexual Functioning Inventory (FSFI)

\begin{tabular}{lcccc}
\hline Sexual life quality & & Number & $\%$ & Cochrane Q-test \\
\hline $\begin{array}{l}\text { Patients with clinically significant sexual } \\
\text { disturbances (FSFI - total } \leq 26.55)\end{array}$ & Visit 1 & 34 & 68.0 & 0.333 \\
\cline { 2 - 5 } & Visit 2 & 26 & 52.0 & $p=0.564$ \\
\hline
\end{tabular}

Table 13. Numbers of women with clinically significant sexual disorders after one and three months of use of Femelis Meno results of examination with the Female Sexual Functioning Inventory (FSFI)

\begin{tabular}{lcccc}
\hline Sexual life quality & & Number & $\%$ & Cochrane Q-test \\
\hline $\begin{array}{l}\text { Patients with clinically significant sexual } \\
\text { disturbances (FSFI - total } \leq 26.55)\end{array}$ & Visit 2 & 26 & 52.0 & 1.800 \\
\cline { 2 - 5 } & Visit 3 & 22 & 44.0 & $p=0.180$ \\
\hline
\end{tabular}


Table 14. Numbers of women with clinically significant sexual disorders before the start and after three months of use of Femelis Meno $(n=20)$ - results of examination with the Female Sexual Functioning Inventory (FSFI)

\begin{tabular}{lccc}
\hline Sexual life quality & & Number & \% \\
\hline $\begin{array}{l}\text { Patients with clinically significant sexual } \\
\text { disturbances (FSFI - total } \leq 26.55)\end{array}$ & Visit 1 & 34 & 68.0 \\
\cline { 2 - 4 } & Visit 3 & 22 & 44.0 \\
\hline
\end{tabular}

Table 15. Distribution of the studied group with respect to satisfaction with the effects of the use of Femelis Meno $(n=50)$

\begin{tabular}{lcc}
\hline $\begin{array}{l}\text { Subjects are satisfied with the effects } \\
\text { of using Femelis Meno }\end{array}$ & Number & $\%$ \\
\hline Certainly satisfied & 28 & 56.0 \\
\hline Rather satisfied & 12 & 24.0 \\
\hline Not very satisfied & 6 & 12.0 \\
\hline Certainly not satisfied & 4 & 8.0 \\
\hline
\end{tabular}

Table 16. Willingness by the studied women to recommend Femelis Meno to other women experiencing menopausal symptoms $(n=50)$

\begin{tabular}{lcc}
\hline $\begin{array}{l}\text { Would you recommend Femelis Meno to } \\
\text { other women suffering from menopausal } \\
\text { symptoms? }\end{array}$ & Number & \\
\hline Certainly yes & 32 & 64.0 \\
\hline Probably yes & 8 & 16.0 \\
\hline Probably not & 8 & 16.0 \\
\hline Certainly not & 2 & 4.0 \\
\hline
\end{tabular}

adverse effects, including allergic ones, were observed in this study.

The argument for prescribing plant-derived therapy to alleviate menopausal symptoms, convincing to both patients and doctors, is product safety, and in particular oncological safety. Study results confirming the favourable safety profile of Femelis Meno were published in recent years. Goldstein et al. [15] assessed the effect of purified PI 82-GC FEM extract on the CYP2D6 enzyme system in an in vitro model, using human liver microsomes for this purpose. Enzymes of cytochrome P460 (CYP) take part in conversion of tamoxifen to 4-hydroxytamoxifen and other metabolites of this drug. The CYP2D6 isoenzyme plays a particular role in this process. As therapy with tamoxifen frequently causes or exacerbates the vasomotor symptoms of the menopausal type, the SSRIs are usually used to alleviate these symptoms. As this pertains most frequently to patients treated for breast cancer, the use of oestrogens for this purpose is contraindicated. Unfortunately, the SSRIS are strong CYP2D6 inhibitors and thus they decrease the anti-oestrogenic efficacy of tamoxifen. The study by Goldstein et al. is part of a trend, intensively explored in recent years, of searching for non-hormonal therapeutic alternatives for patients suffering from menopausal symptoms who have contraindications to oestrogens.
The concentration of the PI 82-GC FEM extracts used in this study was five times as high as the dose used in Femelis Meno. The enzymatic activity of CYP2D6 was inhibited by PI 82-GC FEM to a minimal extent (6.5 to $10.7 \%$ ), as compared to a classical CYP2D6 inhibitor, quinidine, which reduced the activity of this enzyme by more than $84 \%$ at a concentration of $500 \mathrm{nM}$. The authors of this study conclude that the use of the product containing the studied extract in patients treated with tamoxifen who suffer from vasomotor symptoms represents a safe non-hormonal therapeutic option.

Hellström and Muntzing [9] published a study in which they used chromatography to determine the composition of PI 82-GC FEM with respect to presence of phytoestrogenic substances. Additionally, the oestrogenic effect of these extracts was assessed by an uterotrophic assay in an animal model. Very low, biologically ineffective, amounts of daidzein and genistein were found in the studied extracts. As far as formononetin, genistein and biochanin A are concerned, even trace amounts of these isoflavonoids were not found. PI 82-GC FEM did not induce any increase of the uterus weight in immature female rats, even at a high dose $\left(500 \mathrm{mg} / \mathrm{kg}^{-1} \mathrm{day}^{-1}\right)$ of the extract. The results of this study provide evidence that the efficacy of Femelis Meno is not related to the presence of phytoestrogens in its composition or to oestrogenic activity of the extracts contained in this product, which qualifies this product as a non-hormonal phytotherapeutic.

Munoz [16] performed a study that assessed the affinity of the extracts contained in Femelis Meno to the oestrogen receptors. This study showed absence of the oestrogenic effect of the studied plant extracts mediated by oestrogen receptors alpha and beta. Clinical confirmation of this observation was provided by the research of Winther et al. [13], who did not find any significant differences in follicle-stimulating hormone, oestrogen, testosterone and sex hormone-binding globulin levels in patients receiving a product with a composition similar to Femelis Meno. Munoz [16] and Seeger et al. [17] found that the extracts contained in Femelis Meno do not stimulate proliferation of breast cancer cells.

The results of this study showed the significant improvement of general sexual life quality after 3 months of treatment with Femelis Meno. The explanation of this finding is difficult. The impaired quality of sexual life in the menopausal period has very complex and multifactorial determinants. Systemic oestrogen deficiency as 
well as hormone dependent reduction in vaginal and vulvar blood flow cause vaginal dryness and irritation, and promote infections, which leads to discomfort during intercourse. Such non-somatic factors as a successful relationship, support in marriage, sexual awareness and lack of fear in relation to sex have significant positive effects on sexual activity during menopause [18].

\section{Conclusions}

The results of this study suggest that Femelis Meno should be taken into consideration when selecting a therapeutic strategy in cases of menopausal symptoms significantly worsening quality of life, in particular in patients for whom the safety of the therapy is an important issue.

\section{Disclosure}

The authors report no conflict of interests.

\section{References}

1. Buhling KJ, von Studnitz FS, Jantke A, et al. Attitude of German gynecologists towards prescribing HRT before and after the WHI study. Climacteric 2012; 15: 326-331.

2. Baber RJ, Panay N, Fenton A; IMS Writing Group. 2016 IMS Recommendations on women's midlife health and menopause hormone therapy. Climacteric 2016; 19: 109-150.

3. Lobo RA. Where are we 10 years after the Women's Health initiative? J Clin Endocrinol Metab 2012; 98: 1771-1780.

4. de Lemos ML. Effects of soy phytoestrogens genistein and daidzein on breast cancer growth. Ann Pharmacother 2001; 35: 1118-1121.

5. Shike M, Doane AS, Russo L, et al. The effects of soy supplementation on gene expression in breast cancer: a randomized placebo-controlled study. J Natl Cancer Inst 2014; 106: 1-12.

6. Czuczwar P, Paszkowski T, Lisiecki M, et al. The safety and tolerance of phytotherapies in menopausal medicine - a review of the literature. Menopause Rev 2017; 16: 8-11.

7. Druckmann R. A non-hormonal treatment, efficient and safe on climateric symptoms. 11. Congress European Society and Gynecology. A new breakthrough in non-hormonal climacteric symptoms treatment. Prague 21-24 October 2015.

8. Genazzani AR. PSCP: Mechanism of action. 11. Congress of European Society and Gynecology. Prague 21-24 October 2015.

9. Hellström AC, Muntzing J. The pollen extract Femal - a nonestrogenic alternative to hormone therapy in women with menopausal symptoms. Menopause 2012; 19: 825-829.

10. Palacios S. Production and biotechnology of the purified and specific cytoplasm of pollen (PSCP). 11. Congress of European Society and Gynecology. Prague 21-24 October 2015.

11. Rozenberg S. A new breakthrough in non hormonal climacteric symptoms treatment. 11. Congress European Society and Gynecology. Prague 21-24 October 2015

12. Elia D, Mares P. Assessment of the tolerance and effectiveness of a food supplement Séréys (Femal) for menopausal women. Genesis 2008; 135: 12-15.

13. Winther K, Rein E, Hedman C. Femal, a herbal remedy made from pollen extracts, reduces hot flushes and improves quality of life in menopausal women: a randomized, placebo-controlled, parallel study. Climacteric 2005; 8: 162-170.

14. Kimura H, Gruber R. Perimenopausal symptoms such as hot flushes and mood swings are reduced by a standardized pollen and pistil extracts. Poster 2012. Available at: http://www.scicompdf.se/femal/gruber.pdf.
15. Goldstein SR, Espié M, Druckmann R. Does purified Swedish pollen extract, a nonhormonal treatment for vasomotor symptoms, inhibit the CYP2D6 enzyme system? Menopause 2015; 22: 1212-1214.

16. Munoz E. Effect of a PE-F/A on oestrogenic activity. VivaCell Biotechnology $\mathrm{GmbH}$. Internal report. July 2012.

17. Seeger $H$, Ruan X, Neubauer $H$, et al. Membrane-initiated effects of SerelysÒ on proliferation and apoptosis of human breast cancer cells. Gynecol Endocrinol 2018; 34: 353-356.

18. Skrzypulec V, Drosdzol A, Kowalczyk R, et al. Problemy seksualne kobiet w okresie klimakterium w praktyce klinicznej. Menopause Rev 2004; 3: $16-23$. 